\title{
Strategies for Improving Physician-patient Relationship in China Assessing Patient Safety Culture from the Perceptions of Physicians
}

\author{
$\mathrm{Li} \mathrm{Li}^{1}$, Peilin Zhong ${ }^{2}$, Yao Xiao ${ }^{2}$, Hsin-Hung $\mathrm{Wu}^{3,4}$ and Chih-Husan Huang ${ }^{2,5, *}$ \\ ${ }^{1}$ College of Law \& Business, Hubei University of Economics \\ No. 8, Yang Qiaohu Road, Jiangxia, Wuhan City, China \\ ${ }^{2}$ School of Business Administration, Hubei University of Economics \\ No. 8, Yang Qiaohu Road, Jiangxia, Wuhan City, China \\ ${ }^{3}$ Department of Business Administration, National Changhua University of Education \\ No. 2, Shi-Da Road, Changhua, Taiwan \\ ${ }^{4}$ Department of M-Commerce and Multimedia Applications, Asia University \\ No. 500, Lioufeng Rd., Wufeng, Taichung, Taiwan \\ ${ }^{5}$ Institute for Development of Cross-Strait Small and Medium Enterprise \\ No. 8, Yang Qiaohu Road, Jiangxia, Wuhan City, China \\ *Corresponding author's email: tititacer[AT] hbue.edu.cn
}

\begin{abstract}
Creating a better patient safety culture in hospitals has become a critical topic for providing quality medical services globally. In 2014, there were 115 thousand cases of medical disputes in China. Understanding physicians' perceptions toward patient safety is a critical issue for hospitals to monitor safety situations for patients. This study aims to identify physicians' attitudes toward patient safety via the investigation of Sexton et al. (2006)'s Safety Attitude Questionnaire (SAQ), to provide implications for improving medical quality. Pearson's correlation analysis was used to demonstrate the relationships among six patient safety culture dimensions. Regression analysis was subsequently conducted to realize the degree of influence among important dimensions. Physicians was asked to answer the SAQ in a tertiary hospital in China in 2017. The results of Pearson correlation analysis demonstrate that safety climate had strong and positive relationship with working conditions and teamwork climate, respectively. Similarly, regression results illustrated that working conditions, teamwork climate, and teamwork climate had noteworthy effects on safety climate. The examination of patient safety culture from the viewpoints of physicians provides a basis for hospital managers to monitor the medical quality and service for patients. Hospital managers need to pay more efforts to the essentially important elements of patient safety, such as working conditions, teamwork climate, and job satisfaction, to continuously improve physician-patient relationship.
\end{abstract}

Keywords — Physician management, patient safety culture, safety attitudes questionnaire, healthcare

\section{INTRODUCTION}

In recent years, the progress of medicine and the renewal of therapeutic methods have improved the quality of patient treatment. Despite this, however, the occurrence of medical accidents has not reduced as expected; hence, the topic of how to reduce the probability of medical accidents has aroused the attention of the world's medical academics. The data show that 44,000 to 98,000 deaths in American hospitals are caused by preventable medical errors every year, and the total national medical costs can reach $\$ 17$ billion to $\$ 29$ billion [1]. Moreover, medical accidents have led to significant medical dissension, which greatly affects the reputation of hospitals. According to the data of the National Health Commission of the People's Republic of China (NHC), the number of medical disputes in 2013 reached about 70,000 cases. In 2014, 115,000 cases of medical disputes were recorded, and the safety situation of the patients remained severe [2].

Patient safety culture refers to the common attitudes, beliefs, values, and behavior patterns of the management and staff of medical institutions directed toward achieving patient safety [3]. It is a patient-centered service concept among hospital staff [4]. In particular, physicians' understanding of patient safety culture is largely related to the quality of medical services provided, thereby affecting the safety of patients. The development of patient safety culture is 
considered to be an important bridge to promote patient safety. With regard to medical treatment, because physicians are the most knowledgeable about the patients' condition [5], it is important to explore patient safety culture from their perceptions to create better safety standards for patients. Thus, the current study aims to understand the perspectives of physicians on the safety of patients to forge better physician-patient relationships. Additionally, hospital managers can further develop appropriate implementation strategies to offer superior medical services in a competitive healthcarebased industry.

\section{RESEARCH MEHTODS}

The current study aims to assess patient safety culture from the perspective of physicians, using the Safety Attitudes Questionnaire developed by Sexton et al. [6]. As presented in Table 1, the contents of the questionnaire mainly include six dimensions and 30 items. The six variables are teamwork climate, safety climate, job satisfaction, stress recognition, perceptions of management, and working conditions. Teamwork climate implies the atmosphere of cooperation among colleagues, safety climate represents the situation of a hospital's security commitment, job satisfaction is one's positive view of the enthusiasm for work, stress recognition represents one's feelings of work stress, perceptions of management imply feelings about the management style of one's manager, and working conditions describe one's feelings about working conditions and resources [7][8].

A total of 27 valid questionnaires were collected from a tertiary hospital in Hubei province in 2017. Pearson's correlation analysis was used to measure the degree of correlation between the six dimensions of patient safety culture, and regression analysis was used to measure the degree of influence between important dimensions.

Table 1: The Safety Attitude Survey

\begin{tabular}{|c|c|}
\hline Dimension & Question \\
\hline Teamwork Climate & $\begin{array}{l}\text { 1. Nurse input is well received in this clinical area } \\
\text { 2. In this clinical area, it is difficult to speak up if I perceive a problem with patient care } \\
\text { 3. Disagreements in this clinical area are resolved appropriately } \\
\text { 4. I have the support I need from other personnel to care for patients } \\
\text { 5. It is easy for personnel here to ask questions when there is something that they do not } \\
\text { understand } \\
\text { 6. The physicians and nurses here work together as a well-coordinated team }\end{array}$ \\
\hline Safety Climate & $\begin{array}{l}\text { 1. I would feel safe being treated here as a patient } \\
\text { 2. Medical errors are handled appropriately in this clinical area } \\
\text { 3. I know the proper channels to direct questions regarding patient safety in this clinical area } \\
\text { 4. I receive appropriate feedback about my performance } \\
\text { 5. In this clinical area, it is difficult to discuss errors } \\
\text { 6. I am encouraged by my colleagues to report any patient safety concerns I may have } \\
\text { 7. The culture in this clinical area makes it easy to learn from the errors of others }\end{array}$ \\
\hline Job Satisfaction & $\begin{array}{l}\text { 1. I like my job } \\
\text { 2. Working here is like being part of a large family } \\
\text { 3. This is a good place to work } \\
\text { 4. I am proud to work in this clinical area } \\
\text { 5. Morale in this clinical area is high }\end{array}$ \\
\hline Stress Recognition & $\begin{array}{l}\text { 1. When my workload becomes excessive, my performance is impaired } \\
\text { 2. I am less effective at work when fatigued } \\
\text { 3. I am more likely to make errors in tense or hostile situations } \\
\text { 4. Fatigue impairs my performance during emergency situations }\end{array}$ \\
\hline $\begin{array}{l}\text { Perceptions of } \\
\text { Management }\end{array}$ & $\begin{array}{l}\text { 1. Managers supports my daily efforts } \\
\text { 2. Managers do not knowingly compromise patient safety } \\
\text { 3. I get adequate, timely information about events that might affect my work } \\
\text { 4. The levels of staffing in this clinical area are sufficient to handle the number of patients }\end{array}$ \\
\hline Working Conditions & $\begin{array}{l}\text { 1. Problem personnel are dealt with constructively } \\
\text { 2. This hospital does a good job of training new personnel } \\
\text { 3. All the necessary information for diagnostic and therapeutic decisions is routinely } \\
\text { available to me } \\
\text { 4. Trainees in my discipline are adequately supervised }\end{array}$ \\
\hline
\end{tabular}




\section{RESULTS}

The results of current study showed that the Cronbach's $\alpha$ coefficient of all dimensions of patient safety culture was within the range of 0.742 to 0.928 . This suggests that the survey has a certain degree of internal consistency. Based on the Pearson's correlation results in Table 2, the correlation between safety climate and working conditions is the highest $(r=0.857, \mathrm{p}<0.01)$, followed by the correlation between safety climate and teamwork climate $(r=0.809, p<0.01)$. Working conditions were moderately related to the four dimensions except stress recognition.

Table 2: Pearson's correlation analysis for physicians

\begin{tabular}{|c|c|c|c|c|c|c|}
\hline & 1 & 2 & 3 & 4 & 5 & 6 \\
\hline 1.TC & & & & & & \\
\hline 2.SC & $.809^{* * *}$ & & & & & \\
\hline 3.JS & $.558^{* *}$ & $.774^{* *}$ & & & & \\
\hline 4.SR & -.107 & .060 & -.069 & & & \\
\hline 5.PM & .142 & $.474^{*}$ & $.695^{* *}$ & .157 & & \\
\hline 6.WC & $.599^{* *}$ & $.857^{* *}$ & $.688^{* *}$ & .037 & $.602^{* *}$ & \\
\hline
\end{tabular}

Based on correlation analysis, safety climate was selected as the dependent variable in the step of regression analysis. In terms of the influence of each dimension on safety climate, working conditions $(B=0.492, p<0.01)$ was the most significant factor, followed by teamwork climate $(B=0.405, p<0.01)$ and job satisfaction $(B=0269, p<0.05)$, as presented in Table 3.

Table 3: Regression analysis

\begin{tabular}{|c|c|c|c|c|c|c|}
\hline & \multirow[t]{2}{*}{ Model } & \multicolumn{2}{|c|}{ Unstandardized Coefficients } & \multirow{2}{*}{$\begin{array}{c}\text { Standardized } \\
\text { Coefficients }\end{array}$} & \multirow[t]{2}{*}{$\mathbf{t}$} & \multirow[t]{2}{*}{ Sig. } \\
\hline & & $\mathrm{B}$ & Standard Error & & & \\
\hline \multirow{6}{*}{1} & (Constant) & -.519 & .411 & & -1.263 & .220 \\
\hline & Teamwork climate & .405 & .107 & .376 & 3.796 & .001 \\
\hline & Job satisfaction & .369 & .101 & .322 & 2.666 & .014 \\
\hline & Stress recognition & .090 & .050 & .122 & 1.809 & .085 \\
\hline & $\begin{array}{l}\text { Perceptions of } \\
\text { management }\end{array}$ & -.107 & .117 & -.104 & -.902 & .368 \\
\hline & Working conditions & .492 & .112 & .469 & 4.410 & .000 \\
\hline
\end{tabular}

Dependent variable: Safety climate

\section{DISCUSSION}

By investigating patient safety culture from the perspective of physicians, the current study can make the following suggestions.

\subsection{Improvement of safety climate}

Medical quality is the fundamental guarantee for patient safety. An important foundation for preventing and reducing medical disputes can be established by ensuring medical safety and improving the safety climate. This study revealed that the more important the safety climate of physicians, the better their working conditions, and the greater likelihood of positive physician-patient relationships. The main factors that affect medical safety are the lack of safety awareness among medical personnel, an imperfect medical system, and inadequate management. Based on these factors, this study provides the following recommendations:

(1) Improve physicians' awareness of safety management. First of all, every physician must have such awareness to be able to take conscious action. Second, the staff of medical institutions can be regularly trained on health management every year, acquire the relevant legal knowledge related to health management, and convey the content of documents and regulations of the health department on medical safety in a timely manner to patients.

(2) Implement the responsibility system of medical safety management in various departments. All departments need to establish a sound medical safety management system, which is key to ensuring quality medical care. The department 
can conduct some safety and quality checks every week to discuss and analyze medical errors or accidents that have occurred, determine the reasons, propose improvement measures, and eliminate hidden dangers in time.

\subsection{Improvement of job satisfaction}

Thorough professionalism, high occupational risk, and demanding tasks characterize the profession of physicians. Their working environments have become passive and tense because of the intense medical duties and patient relationships in recent years, the increase of medical disputes, and the gradual reduction of work autonomy. Therefore, the satisfaction of doctors gradually decreases. However, the reduction of job satisfaction can inhibit the performance of medical staff, thereby making patients dissatisfied, which in turn makes the relationship between physicians and patients even more strained and inconducive to social development. The study shows that the higher the job satisfaction among physicians, the better their perceptions of management and their working conditions. This study thus proposes the following improvements:

(1) Enhance physicians' sense of identity and strengthen their sense of belonging to departments. The factors that affect physicians' sense of belonging include social value judgment, fairness of distribution, work pressure, and so on. When the level of treatment does not reflect the physicians' technical competency and labor value, it will reduce the enthusiasm of physicians. Research shows that the construction of welfare, assessment, and reward systems significantly impacts turnover intention [9]. Therefore, it is necessary to strengthen the sense of belonging of physicians to their departments. There are several ways this can be done including, for example, by strengthening the communication between the doctors and patients, guiding the media/public opinion reasonably, objectively reporting all medical disputes, establishing a good performance appraisal mechanism, and attaching importance to and managing the operation of the evaluation mechanism.

(2) Attach importance to the development of the internal culture of departments. Physicians are often stressed because of their demanding tasks, promotions, and job titles, and a good internal culture can help reduce their pressure so that they can make effective psychological adjustments. First of all, the superior medical staff should have a standard role to play, while the manager should have a strong sense of responsibility, should strengthen the care provided to the lower medical and nursing staff, and always pay heed to the psychological state of the medical staff. In addition, health care workers should help each other in relieving stress through frequent communication and by overcoming medical difficulties together.

(3) Establish a scientific performance assessment program. In the selection of professional titles of medical staff, too much attention has been paid to the scientific research level of doctors, which has caused a certain kind of pressure on clinical doctors and affected their enthusiasm. Therefore, physicians are often divided into two categories: clinical and academic, and their performance appraisal is conducted according to different standards. Because clinical doctors are responsible for the diagnosis and treatment of patients, their promotion and salary are related to clinical work and are not subject to the limitations of papers and titles; however, academic doctors are responsible for academic research and teaching. Their promotion wages are related to their academic work and reduce the pressure on physicians with regard to holding professional titles and getting promotions.

\section{CONCLUSION}

In summary, we suggest that hospital managers should spare no effort to establish patient safety cultures, which can greatly reduce the occurrence of preventable medical accidents, decrease medical costs, and ensure the safety of patients. Our findings have practical implications for hospital managers to develop strategies to strengthen patient safety culture and forge better physician-patient relationships.

\section{ACKNOWLEDGEMENT}

This study was supported by Hubei Provincial Department of Education with the grant number of B2018124.

\section{REFERENCES}

[1] Zhang, Z. (2006). Patient safety: concepts and examples. Medicine and philosophy, vol. 27, no. 6, pp. 12-16.

[2] National Health and Family Planning Commission of the People's Republic of China (NHC). Health planning reformation and development. Retrieved July $3, \quad 2018$ from http://www.nhfpc.gov.cn/libin/ldhd1/201403/5005938c3925434c93b58e1d2c6b46e3.shtml).

[3] Sammer, C. E., Lykens, K., Singh, K. P., Mains, D. A. \& Lackan, N. A. (2010). What is patient safety culture? A review of the literature. Journal of Nursing Scholarship, vol. 42, no. 2, pp. 156-165. 
[4] Huang, C. H, Wu, H. H, Lee, Y. C., Li, L. \& Wu, C. F. (2018). Creating a better patient safety culture in Taiwan: the viewpoints of physicians and registered nurses. Hospital Practice and Research, vol. 2, no. 4, pp. 122-124.

[5] Nguyen, G., Gambashidze, N., Ilyas, S. A. \& Pascu, D. (2015). Validation of the safety attitudes questionnaire (short form 2006) in Italian in hospitals in the northeast of Italy. BMC Health Service Research, vol. 15, p. 284.

[6] Sexton, J., Helmreich, R., Neilands, T., Rowan, K., Vella, K., Boyden, J., Roberts, P. \& Thomas, E. (2006). The safety attitudes questionnaire: Psychometric properties, benchmarking data, and emerging research. BMC Health Service Research, vol. 6, p. 44.

[7] Lee, Y. C., Weng, S. J., Huang, C. H., Hsieh, W. L., Hsieh, L. P. \& Wu, H. H. (2017). A longitudinal study of identifying critical factors of patient safety culture in Taiwan. Journal of Testing and Evaluation, vol. 45, no. 3, pp. 1029-1044.

[8] Huang, C. H., Wu, H. H, \& Lee, Y. C. (2018). The perceptions of patient safety culture: a difference between physicians and nurses in Taiwan. Applied Nursing Research, vol. 40, pp. 39-44.

[9] Singer, S. J., Gaba, D. M., Geppert, J. J., Sinaiko, A. D., Howard, S. K. S. \& Park, K. C. (2003). The culture of safety: results of an organization-wide survey in 15 California hospitals. BMJ Quality \& Safety, vol. 12, no. 2, pp. 112-118. 